\title{
MEASURING UNEMPLOYMENT: A COMPOSITION MODEL
}

\author{
L. Fraser Jackson \\ Victoria University of Wellington
}

\begin{abstract}
In looking at statistics of the labour market, the labour force status categories are often considered as independent, but when expressed as proportions they are observations over a simplex of nonnegative components summing to 1. This leads to serious deficiencies in the conventional tools of analysis, and a framework commonly referred to as compositional modelling has been developed to address them. This paper explores the application of these tools to labour force data and demonstrates simple consistent patterns between job search (unemployment) and current participation levels across both aggregate and age and gender sub populations. Unlike previous uses of composition models in labour market studies we use a simple transform with a direct interpretation for our analysis.
\end{abstract}

\section{Empirical Analysis of Unemployment Data.}

It is not surprising that figures on employment and unemployment from the quarterly reports of the Household Labour Force Survey (HLFS) are at the centre of much economic policy discussion. These surveys are conducted in nearly all developed countries and small changes in the percentage rates observed are often quoted as measures of policy success or failure. They use internationally agreed definitions. In a paper in 1897 Karl Pearson showed that data presented as percentages commonly leads to misleading patterns of association and correlation. The issues he raised are usually ignored in applying conventional multivariate statistics to HLFS data. This paper shows that there is a clear pattern in the composition across the labour force categories associated with the observed employment participation rate and discusses some potential implications.

The large strong association between unemployment and the aggregate observed demand means that an infinite demand for labour at the going wage is inconsistent with the data. The variation observed is consistent with an alternative interpretation that demand is inelastic and demand side changes are the predominant source of change. Many uses of the micro data in the surveys focus on labour supply, but they generally make the strong assumption that there is an infinite demand for labour at the going wage rate. Estimates based on those studies often play a key part in policy discussions, including the impacts of tax policy.

The paper applies the composition analysis developed by Aitchison(1986) and expanded more recently by many others. Expositions by Boogaart and Tolosana-Delgado(2013) and PawlowskyGlahn and Buccianti (2011) include the historical development and list extensive references. An important step was the development of isometric log ratios by Egozcue et al(2003) as these preserve the relationship between points and an appropriate distance measure. The tools have been widely applied in geochemical analysis but are not as widely appreciated in social and economic statistics as 
they deserve to be. Fry(2011) reviews applications in economics, and Anyadike-Danes $(2004,2007)$ showed that the percentage unemployed was not an adequate descriptor of the regional differences in English labour markets using these tools. Bergman(2008) developed a simple VAR model for predictions of Swedish labour markets without extensive interpretive comment. Our notation and description is focused on the area of application. The references give a technical development of the tools.

The HLFS data treats the population as composed of three labour force status groups. With only three categories there are limited options in analysis. Some analysts focus on a labour supply as a primary category, others on employment status as the primary concept. Transitions between categories and large gross flows between them, make them difficult to interpret. From the perspective of this paper the whole population can lie in any one of the categories and transitions between them can occur at any time. The potential labour force is the whole population. Obviously heterogeneity of members of the population means that not all seek work at a particular time or fit the requirements of employers. Our results provide a framework which needs to be considered when detailed consideration of such heterogeneity is the subject of further work.

Jones and Riddell(1997) looked at the micro-behaviour of persons in these groups and showed that for Canadian data a fourth group would provide a better match with micro-behaviour probabilities for changes in labour force status. Their paper highlights that these are surveys of micro data but they have a primary use in discussion of macro aggregates and the extent of availability for employment. The analysis in this paper examines the macro behaviour, in the sense that we are looking at the aggregation of many individual decisions, and like Jones and Riddell it focuses on the extent to which it shows consistent empirical features.

The models in this paper are for the total working age population. An analysis by subpopulation categories using the same general model structure is also reported. This adds a supply side dimension and indicates some ways that the available measures probably give a quite partial picture of what is happening.

In Section 2 the basic statistical analysis framework is outlined. In Section 3 it is applied to aggregate data ignoring gender. In Section 4 we generalise to a labour market with labour from groups distinguished by age and gender but each regarded as a sub population in an independent market. This gives insights into some limits of the data and issues in its interpretation. In Section 5 we examine the data from the perspective of all persons in an age group to explore links between male and female choices. In Section 6 we use these analyses to discuss identification issues raised by this data.

\section{A simple analytical framework.}

Denote the three main labour force categories by $E$ (employed), $U$ (unemployed) and $N$ (not in the labour force) and their total $P$ (the working age population). Those in $E$ have some paid work and may also do job search but it is not recorded. Any person with some paid work of an hour or more, is not regarded as unemployed. Those in $U$ do not have any paid work, but have undertaken at least one of a set of job search activities. Those in $\mathrm{N}$ do not have any paid work and have not reported any of the required job search activities. Let $W$ represent those without market work, so $W=U+N$. (e, $u, n)$ and $w$ denote the proportions of the population in each group. A second letter $m$ or $f$ is 
appended to denote gender groups, such as em for persons employed who are male. The common usage of expressing proportions as percentages is sometimes used. Note that $u=U / P$, is not the conventional unemployment rate $u^{c}=u /(u+e)$. Using e and $u^{c}$ enables calculation of $e, u$ and $n$ but $\mathrm{e}$ and $\mathrm{u}^{\mathrm{c}}$ are ratios which relate to two overlapping populations and thus difficult to interpret. Central ideas in this analysis are that the proportions relate to the same population, that $e+u+n=$ 1 and while there are three proportions there are only two degrees of freedom, hence any change in one requires some change in the others.

To reduce the number of brackets, we write $\ln (u / n)$ as $\ln u / n$ where $\ln$ is the natural logarithm, and the argument is the whole expression following the function name. We use the comma as a separator for items in lists as in the R programming language.

Each observation can be represented by the vector

$(\ln e, \ln u, \ln n)$

and can be re expressed using one element as reference to form ratios (called additive log ratios)

$\operatorname{alr}(e, u, n)=(\ln e / n, \ln u / n, \ln n / n)$

The last element is a zero, indicating there are just two degrees of freedom and the three variate data lies in a two dimensional space. The choice of comparison element is arbitrary, but Aitchison(1986) derived conditions under which it does not modify the conclusions. To have a symmetric procedure he proposed using centralised log ratios with the geometric mean of the components, $\mathrm{g}=(\mathrm{e} \text { u } \mathrm{n})^{1 / 3}$ as divisor.

Let $c \mid r(e, u, n)=(\ln e / g, \ln u / g, \ln n / g)$ represent the transform to centralised log ratios. Here the sum of the elements is zero. For a matrix of $(e, u, m)$ data the same notation specifies a new matrix by applying the clr function to each row. To convert this space to a two dimensional space where the conventional statistical tools can be applied, Egozcue et al (2003) developed isometric log ratios (ilr) using a simple orthogonal linear transform $\mathrm{H}$ from the 3 dimensional representation of values with the clr to a 2 dimensional space of real numbers. The advantages of using ilr are that it is both an isomorphic and an isometric transform, conventional measures of distance apply and the concept of projection so important in statistics in real space can be used.

For general compositions with $\mathrm{D}$ components, the matrix of the transform $\mathrm{H}$ is of shape $\mathrm{D}-1$ rows and $\mathrm{D}$ columns and the isometric log ratios are obtained with a matrix product

$($ ilr $x)=(\operatorname{clr} x) H^{\prime}$

where $H H^{\prime}=I_{D-1}$ and $H^{\prime} H=I_{D}-\mathbf{1}_{D}$ with $I_{D}$ an identity matrix and $\mathbf{1}_{D}$ a $D$ dimensional square matrix with each element $1 / D$. The inverse relationship is

$(\operatorname{clr} x)=(i \operatorname{lr} x) H$

and these values are easily transformed back to the original composition, $(e, u, n)$ or a D -element vector in general. If an analyst is interested in a set of D-1 linear contrasts between the $D$ categories, the $\mathrm{H}$ matrix can be found by listing the contrasts as rows of a matrix and calculating its Gram Schmidt orthogonalization. Details of how to express the contrasts are given by Egozcue(2003) and Boogart and Tolosano-Delgado(2013). 
Procedures of this kind are common in statistics. The data is subject to a transformation, an analysis of the transformed data is constructed, and then the results are transformed back to the original units.

\section{Aggregate Behaviour}

The data used is a table of quarterly observations of labour force status for persons 15 years and over, distinguished by age and sex, from the New Zealand HLFS from 1986Q1 through 2014Q2. This section uses the national totals. The subpopulation of those 15 and under 65 is also of interest, since there is a universal age benefit for persons over 65, they are not eligible to receive an unemployment benefit and they seldom do job search in a manner which would identify them as unemployed. We omit treatment of them for space reasons.

Consider two contrasts between the categories. The first compares those with jobs and those without, and the second whether those without jobs undertake search activities. These lead to a transform matrix $\mathrm{H}$, defined by

$H=\begin{array}{ccc}0.816497 & -0.408248 & -0.408248 \\ 0.0 & 0.707107 & -0.707107\end{array}$

The resulting ilr coordinates have the form

$\left(e^{*}, u^{*}\right)=\left(m_{1} \ln e /(u n)^{1 / 2}, m_{2} \ln u^{+} /\left(1-u^{+}\right)\right)$

where $u^{+}$is $u /(u+n)$ and $m_{1}$ and $m_{2}$ are multipliers to maintain the condition that the clr values obtained in the inverse described above must sum to zero. An alternative way of thinking of this vector is to regard the first element as the log of a geometric mean , $0.5 *((\ln e / u)+\ln e / n)$ which is a comparison of those employed versus each alternative for those without work. The second is $\ln u / n$ or the odds ratio of engaging in search which will depend on the costs of search, the probability of success and the importance and magnitude of the income effect from having work. From (1) we can go back to the clr values and then simply back to values in the original $(e, u, n)$ space.

An examination of the pair wise scatter plots of the clr values shows a break in pattern associated with the Global Financial Crisis(GFC). This is also clearly apparent in a plot of the data for the ilr values in Figure 1 which illustrates the association of these two variables, and Figure 2 translates back into the original categories. The green line traces the sequence of observed points in blue, and the red line a fitted model. The proportions of those with work and those without work are perfectly inversely related, but within the group without work, if the proportionate change in $\mathrm{u}$ is more extreme than the proportionate change in $n$, and both changes are of the same sign, the odds of seeking work declines as the proportion in work rises. There is a break in the behaviour with the global financial crisis and the business cycle dates of Hall and MacDermott(2014) are used to add a term from 2008Q1 to the model to incorporate it. The fitted line is for the model

$$
u_{t}^{*}=b_{0}+b_{1} e^{*}{ }_{t}+b_{2} d_{1 t}+z_{t}
$$




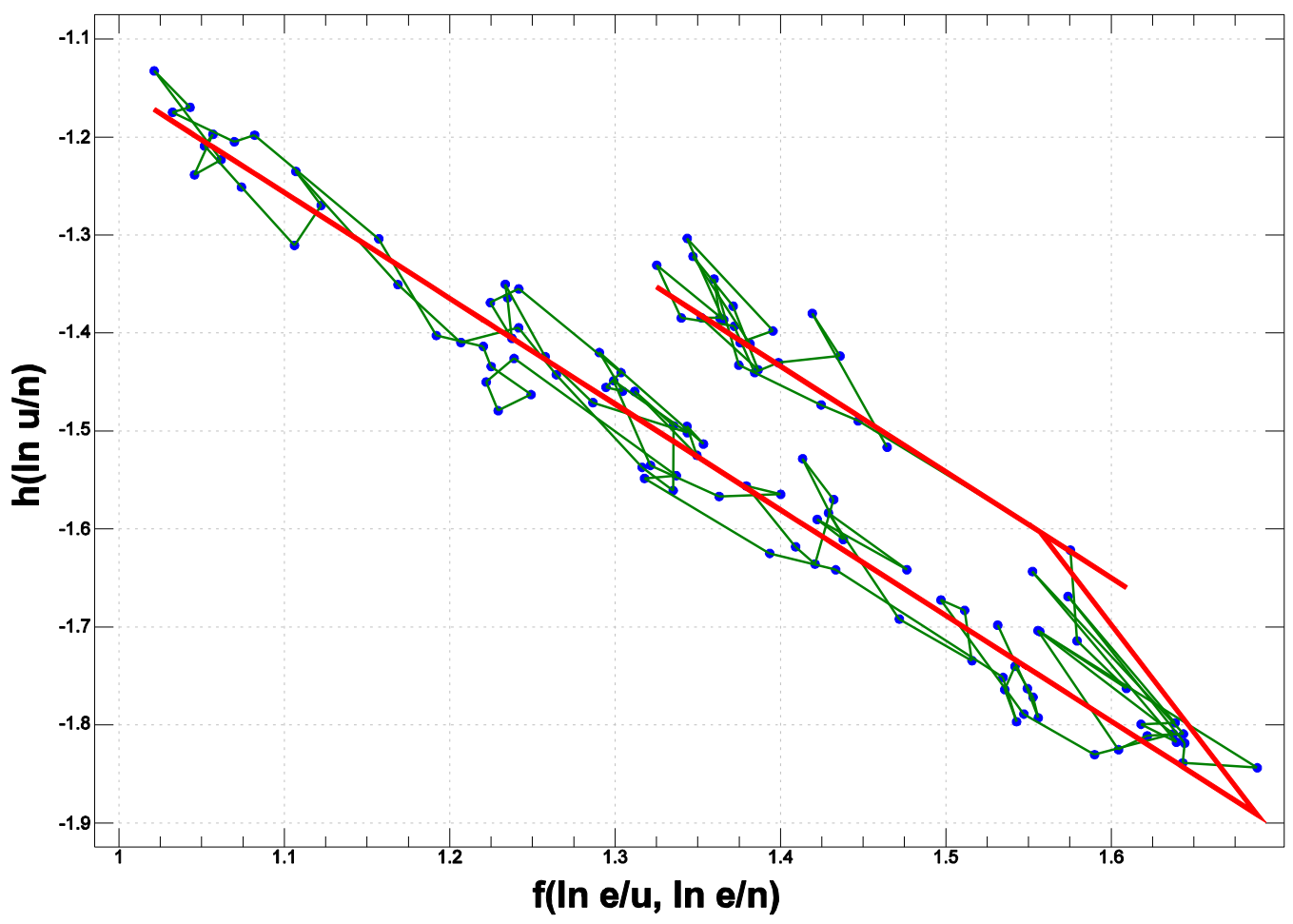

Figure 2 Employment and Job Search 1986Q1 - 2014Q2 - Original scales

Model (2) Employment and Job Search

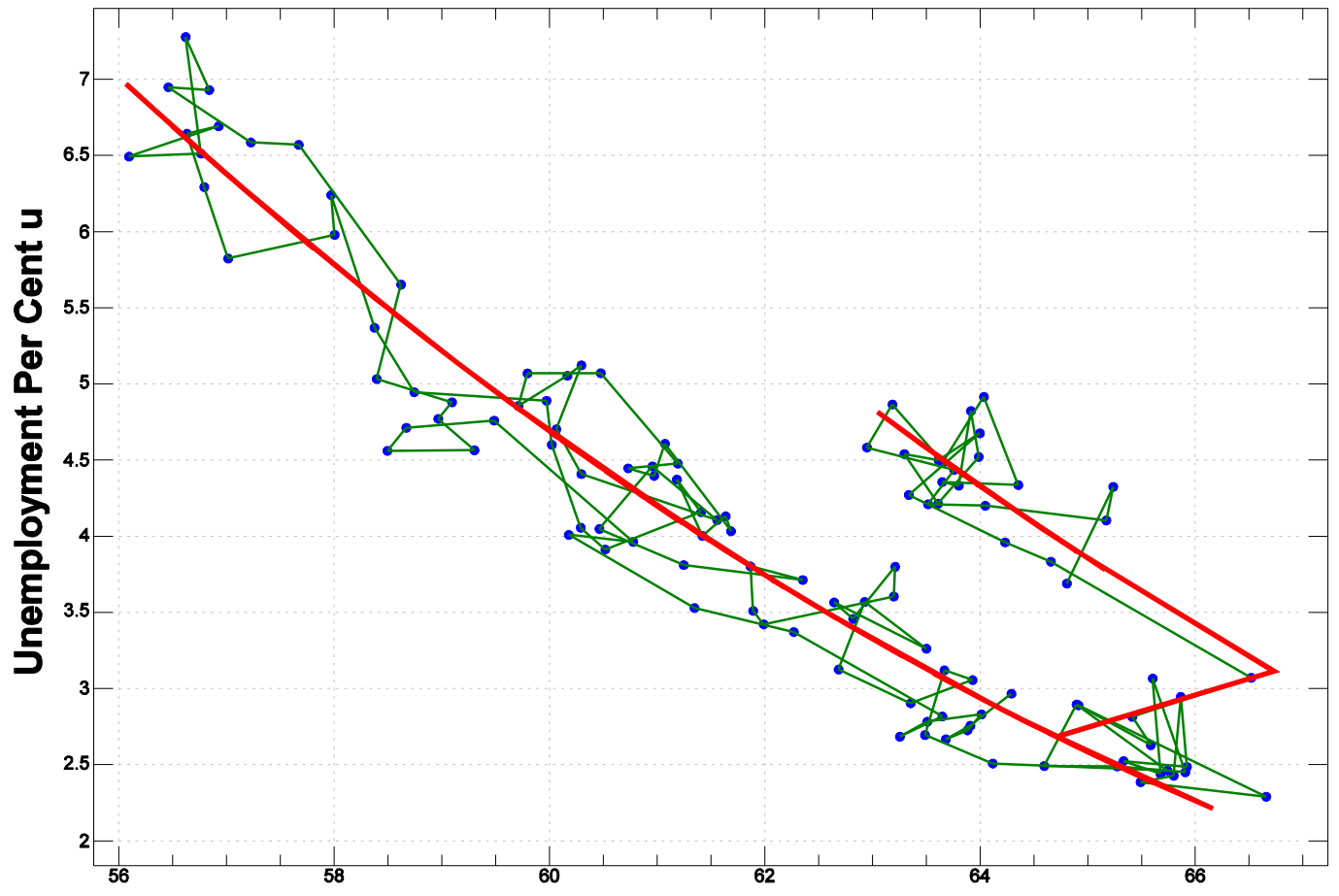

Employment Per Cent e 
with $\mathrm{e}_{1}^{*}$ and $\mathrm{u}{ }_{1}^{*}$ the isometric log ratio values given in equation (1), $\mathrm{d}_{1 \mathrm{t}}=0$ until 2007Q4 and 1 thereafter and $z$ remaining errors. In some subpopulations there are trends in the data. To consider those cases fit the model

$$
u_{t}^{*}=b_{0}+b_{1} e^{*}{ }_{t}+b_{2} d_{1 t}+b_{3} d_{2 t}+z_{t}
$$

where $d_{2 t}$ specifies a linear trend over the whole period with $d_{2 t}=(t-1) / 114$ so the coefficient is of similar scale to the others. The additional term gives a significant improvement in the fit. The global picture for the whole population using model (3) is provided in Figures 3 and 4.

Figure 3 Employment and Job Search 1986Q1 - 2014Q2 - ilr scales Model (3)

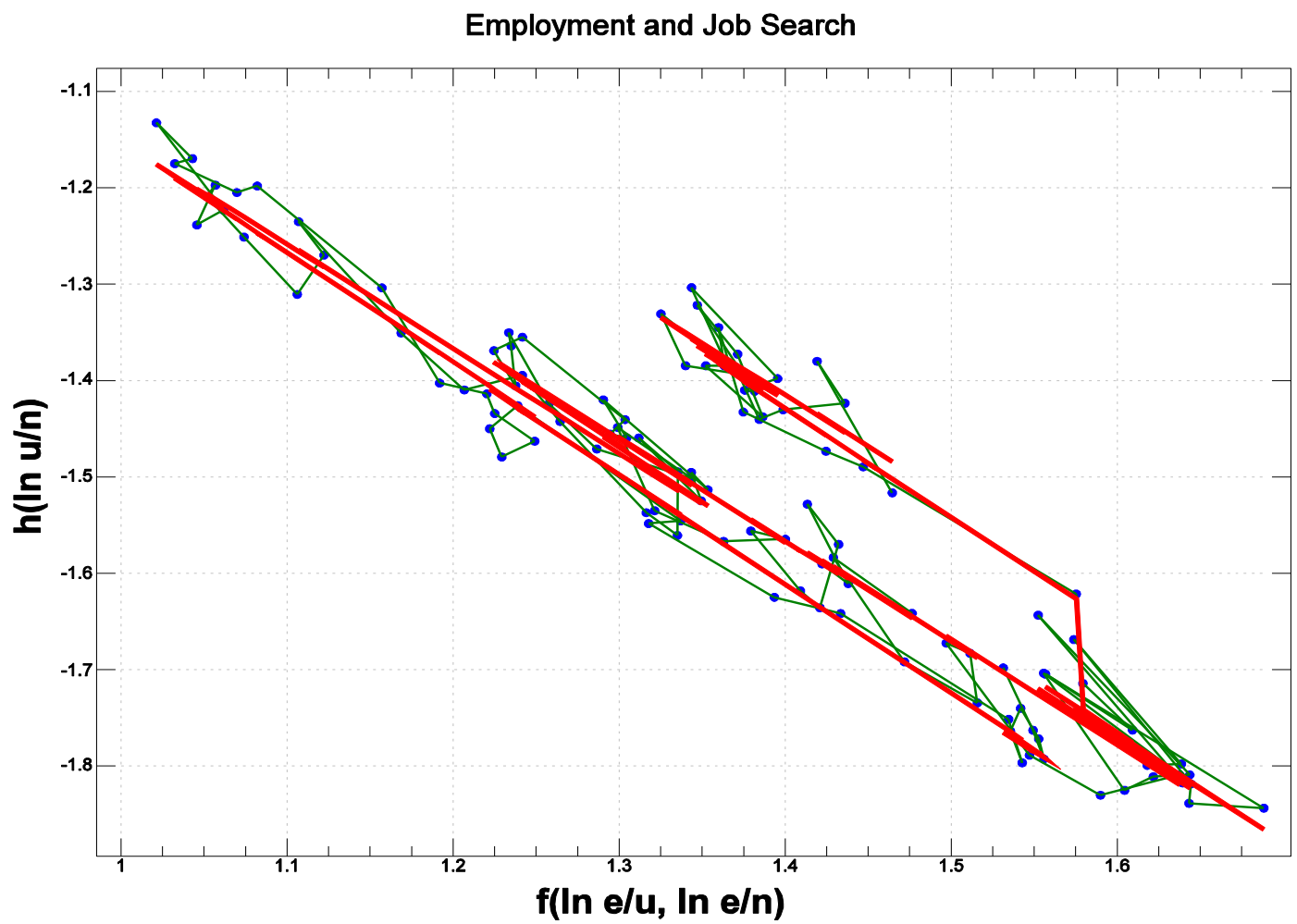

Model 3 has also been fitted to the subpopulations of males and females. The trend component is of different sign for these two groups, with the female positive trend dominating in the total. The female participation rate has grown significantly and with unchanged behaviour that would reduce the expected unemployment. To get a positive component there would need to be an even larger increase in the proportion of females pursuing job search activities.

The residuals show some autocorrelation but treating these models within a dynamic framework is an area for further research. The sampling errors of the data may seriously limit the ability to explore the dynamics for sub populations.

Figure 4 Employment and Job Search 1986Q1 - 2014Q2 - Original scales Model (3) 


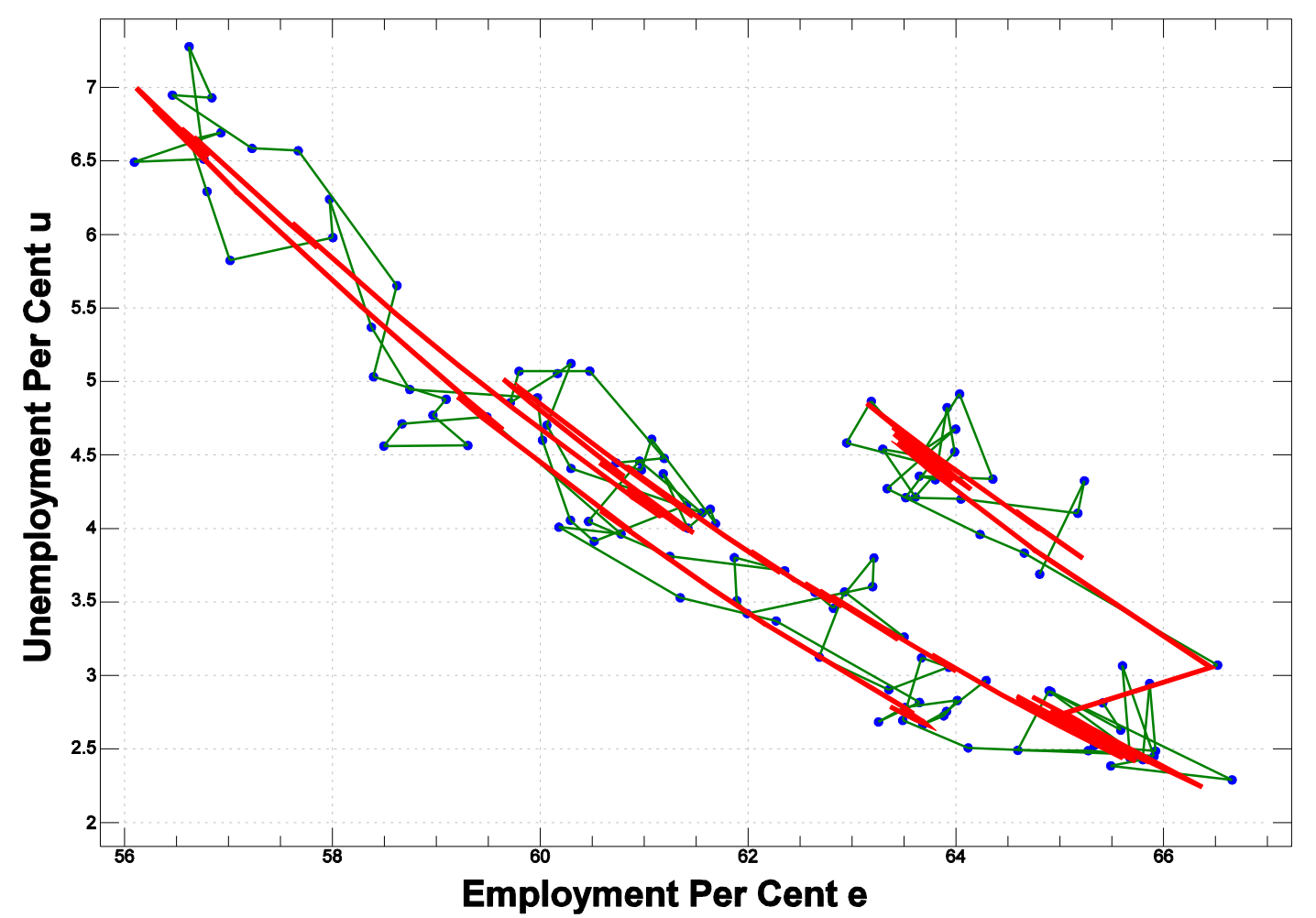

The picture in these aggregate plots can be summarised as follows. (1) Expressing the relationships in log ratios appears to capture the linkages between the variables and gives nearly linear patterns. (2) The mean of $\mathrm{In} e / \mathrm{u}$ and $\mathrm{In} \mathrm{e} / \mathrm{n}$ is a useful summary of employment participation in relation to the other categories. (3) The logit of the probability of a person without work engaging in job search declines with increased participation. (4) There is a very clear pattern of unemployment rates being associated with changes in the employment participation rate. (5) The labour force using the conventional definition varies by almost twice as much as changes in unemployment in New Zealand. (6) There has been a shift in the job search behaviour at given employment rates with the post GFC business cycle in New Zealand. (7) There has been in addition a modest trend shift in the relationship over the last 28 years towards higher levels of search behaviour at a given participation level but this trend has been in opposite directions for males and females, with the latter having larger increases in search behaviour.

\section{Age and Gender Sub-Populations}

The model framework applied above to the whole population can be applied to each age and gender subpopulation. In this analysis all sub populations are regarded as behaving independently, and their job search behaviour depends only on their own experience of the labour market. That is a common practise in participation studies for gender and ethnic subgroups. The fitted regressions for Model (3) by age and gender groups are given in Table 1 and 2 . Model 3 provides a significantly better fit

than Model (2) for almost all sub population groups, and the trend component generally has a larger $\mathrm{t}$-statistic than the post-GFC break term. A similar model but using the total participation rate rather 
than the subpopulation rate was explored. It gave similar results but the $\mathrm{R}$ squared values were smaller in over two thirds of cases.

The fact that $\mathrm{u}^{*}$ is clearly related to $\mathrm{e}^{*}$ in nearly all of these groups means we must include the experienced employment situation in considering participation decisions. In all of the 35 subpopulation groups examined, as employment participation changes the odds of job search behaviour by those without work changes in an inverse direction. Trying to infer desired participation while ignoring the constraint of current job opportunities and the current experienced job participation is clearly fallacious.

Interpreting the coefficients in Table 1 and 2 is difficult. The variable $\mathrm{e}^{*}$ depends on the square root of the two proportions $\mathrm{u}$ and $\mathrm{n}$ in its denominator. This has a maximum when $\mathrm{u}=\mathrm{n}$ and can be considerably smaller as the split between them increases. Its maximum also depends on e. This means that the location within the simplex defined by the components $e, u$ and $n$ modifies the proportionate response to changes in e. Since male and female sub-populations lie in different positions in this space we would expect different patterns of response.

The participation in job search depends on age and gender and existing work participation. By expressing the search behaviour in terms of $\mathrm{u}^{+}$we get a very different picture of unemployment. Mean ratios of job search measured by $\mathrm{u}^{+}$at the mean employment participation rate for each age and sex group in the data are given in Table 3. For males the rate rises quickly to a peak, and $\mathrm{u}^{+}$can go as high as 60 percent for quarterly observations. Any sense that there is a failure of interest in work is clearly false in the light of such intense search behaviour.

\section{A Six Category Model With Gender Differences}

Section 4 ignored any interaction of age and gender subpopulations. Consider the subpopulation of all persons distinguished by gender, thereby focusing on behaviour of an age cohort. There are then six categories in the composition, and we are looking at the joint decisions of people in an age group and the ways in which they choose to respond to their labour market environment. Male and female participation rates are expressed as a percentage of the total population, not just the male and female groups. This enables us to look at the joint labour market activity choices with a gender balance given by demographic structure.

There are many alternative coordinate systems to span the five dimensional space of the data. Using the matrix $\mathrm{H}$ in Table 3 below we can examine the behaviour in a manner consistent with the structure used in Section 3.

Table 3 Orthogonal Transform to convert clr coordinates to ilr values.

\begin{tabular}{|c|c|c|c|c|c|c|}
\hline & em & um & $\mathrm{nm}$ & ef & uf & $\mathrm{nf}$ \\
\hline ilr(e/w) & 0.5774 & -0.2887 & -0.2887 & 0.5774 & -0.2887 & -0.2887 \\
\hline ilr(um/nm) & 0 & 0.7071 & -0.7071 & 0 & 0 & 0 \\
\hline ilr(uf/nf) & 0 & 0 & 0 & 0 & 0.7071 & -0.7071 \\
\hline ilr(em/ef) & 0.7071 & 0 & 0 & -0.7071 & 0 & 0 \\
\hline ilr(wm/wf) & 0 & 0.5000 & 0.5000 & 0 & -0.5000 & -0.5000 \\
\hline
\end{tabular}


The first three components of the ilr transform retain 94.6 percent of the variance of the data. The correlations between these variables are given in Table 4 .

Table 4 Correlation of ilr coordinates

\begin{tabular}{|c|c|c|c|c|c|}
\hline & ilr(e/w) & ilr(um/nm) & ilr(uf/nf) & ilr(em/ef) & ilr(wm/wf) \\
\hline $\operatorname{ilr}(e / w)$ & 1 & -0.966 & -0.708 & -0.296 & -0.729 \\
\hline ilr(um/nm) & -0.966 & 1 & 0.671 & 0.377 & 0.697 \\
\hline ilr(uf/nf) & -0.708 & 0.671 & 1 & -0.304 & 0.427 \\
\hline ilr(em/ef) & -0.296 & 0.377 & -0.304 & 1 & -0.058 \\
\hline ilr(wm/wf) & -0.729 & 0.697 & 0.427 & -0.058 & 1 \\
\hline
\end{tabular}

Clearly the male odds for unemployment are highly correlated with the overall employment measure. A graphical picture of the female coordinates shows significant differences between the periods 1986Q1-1991Q2, 1991Q3-2007Q4 and 2008Q1-2014Q2 aligned with business cycles as identified by Hall and MacDermott.

Using a similar framework to Section 3 define Model (4)

ilr um/nm $=b_{0}+b_{1}\left(\right.$ ilr e/w) $+b_{2} d_{1 t}+b_{3} d_{2 t}+z_{t}$

ilr uf/nf $=b_{0}+b_{1}$ (ilre/w) $+b_{2} d_{1 t}+b_{3} d_{2 t}+z_{t}$

Figure 5 Time series plot of odds of Job search by Males and Females

Trace of Actual and Fit For Model 4 1986Q1 to 2014Q2

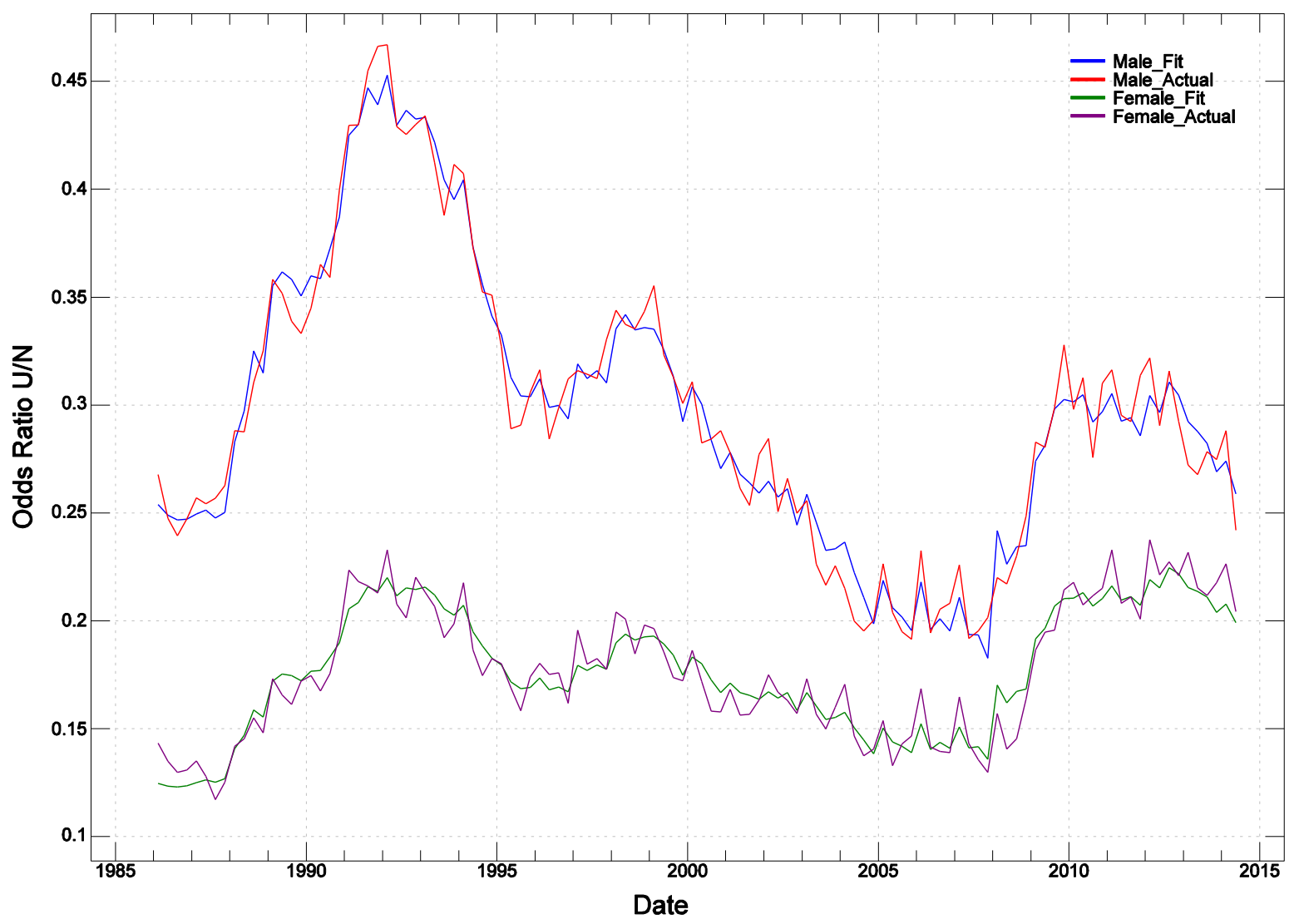


Note that ilr e/w now involves a weighted mean of the clr values of all of the six categories. Figure 5 gives the fitted models. As with the earlier regressions there is no attempt to eliminate the serial correlation of the residuals. Some of it is probably associated with seasonal fluctuations. These regressions show that a very simple model fits the observed split between the conventional unemployment and non labour labour force categories for both gender groups. In the model a measure which is a weighted mean of all the participation rates but distinguishing those in and out of work, acts as the primary driver. The $\mathrm{u}$ and the $\mathrm{n}$ status distinguished by gender play a part in determining the weight associated with those out of work and in modifying the odds ratio for persons being unemployed. Figure 5 illustrates that this simple model generates a different outcome for the development of male and female unemployment, but without additional variables we cannot identify how this is related to either demand or supply side factors.

There has been a significant shift in gender balance of those within employment but it is a slow trend and contributed relatively little directly to the total variance in the data. The business cycle dummy also plays a role in the fit in Figure 5.

\section{Some perspectives on this analysis}

This paper has shown that employment participation is a dominant descriptor of the HLFS labour force. Composition tools respect the geometry of the simplex structure and use contrasts which reflect searching for work under a constraint on jobs available. It explores out of equilibrium behaviour, which Solow(1990) argued plays a major role determining what we observe. However to derive causal patterns of interest it is necessary to introduce factors which reflect the truism that to identify demand we need factors changing supply and to identify the supply function we need changes in demand. However Doing so would replace the trend and dummy terms of model (3). However in all of the aggregate and sub population studies, the probability that an unemployed worker will engage in search behaviour is directly related to the proportion of the population not in work. That is what would be expected if there is variation in demand, a stable labour supply in excess of demand and stable reservation wages which Solow viewed as having a strong common sense foundation. This model therefore provides a basis for further development. The picture is consistent with Keynes(1936) remark '... more labour would, as a rule, be forthcoming at the existing money-wage if it were demanded.' Search models have played in a big part in labour economics over the past four decades, but have failed to address the huge disequilibrium issues. The big search problems are for employers to find new job opportunities, and potential workers to find one of the jobs available. This paper has taken the view that unemployment statistics are about the second of these problems and do not provide an adequate measure of the number available for work.

The observations of model (3) have the strong implication that at a higher participation rate the observed unemployment would be lower. That raises the question of whether at that higher participation the labour force is unchanged. For all of the population subgroups a simple calculation shows that using the conventional measure, the labour force tends to be higher at higher participation rates. The fitted models show the possibility of different behaviour, but over the observed range all generate an increase in the estimated labour force at higher participation rates except those for women from 45 to 54 where the estimated labour force showed little variation. 
A first step in going beyond these models is to explore the effect of vacancies. The New Zealand data is inadequate to derive confident results, but some studies to be reported elsewhere using countries with good vacancy data suggest that vacancies play a key role in modifying the search behaviour of those without a job and hence estimates of unemployment and available labour. A further step would be to use models similar to model (4) to explore both demand and supply factors influencing the gender distribution of employment.

\section{References}

Aitchison, J. (1986). The Statistical Analysis of compositional data. Monographs on statistics and applied probability. London: Chapman \& Hall. (Reprinted in 2003 with additional material by the Blackburn Press). 416 p.

Anyadike-Danes, M. (2004). The real north-south divide? Regional gradients in UK male nonemplopyment. Regional Studies, 38(1),85-95.

Anyadike-Danes, M. (2007). How well are women doing? Female non-employment across UK regions. Applied Economics, 39(14),1843-1854.

Boogaart, K. Gerald van den and Tolosana-Delgado, Raimon. (2013). Analysing Compositional Data with R. Springer: Heidelberg. New York, Dordrecht, London.

Egozcue, J.J., Pawlowsky-Glahn, V., Mateu-Figueras, G., \& Barcelo-Vidal, C. (2003). Isometric logratio transformation for compositional data analysis. Mathematical Geology, 35(3), 279-300.

Hall, Viv B. and McDermott, C. John (2014). Recessions and Recoveries in New Zealand' Post-Second World War Business Cycles. Discussion Paper DP2014/02. Reserve Bank of New Zealand.

Keynes, John Maynard. (1936). The General Theory of Employment Interest and Money. London, Macmillan. First edition. (1960 printing) P.7.

Fry, Tim. (2011). Chapter 23. Applications in Economics. In Pawlowsky-Glahn, Vera and Buccianti.Antonella(eds). (2011). Compositional Data Analysis: Theory and Applications. . Chichester: John Wiley and Sons.

Jones, Stephen R.G. and Riddell, W. Craig. (1999). The measurement of Unemployment: An Empirical Approach. Econometrica. 67(1), 147-162.

Pawlowsky-Glahn, Vera and Buccianti, Antonella (eds). (2011). Compositional Data Analysis: Theory and Applications. . Chichester: John Wiley and Sons.

Solow, Robert M. (1990) The Labor Market as a Social Institution. Cambridge, Mass. Basil Blackwell Inc. 
Table 1 Regression Coefficients and t-statistics for Age and Gender Groups

\begin{tabular}{|c|c|c|c|c|c|c|c|}
\hline \multirow[b]{2}{*}{ Aged } & \multicolumn{3}{|c|}{ Male } & \multicolumn{2}{|l|}{ Female } & \multicolumn{2}{|l|}{ Total } \\
\hline & 15-19 Years & $\begin{array}{r}0.671 \\
-0.261 \\
0.173 \\
-0.585\end{array}$ & $\begin{array}{r}13.351 \\
-4.508 \\
4.545 \\
-11.128\end{array}$ & $\begin{array}{r}0.803 \\
-0.362 \\
0.097 \\
0.328\end{array}$ & $\begin{array}{r}14.757 \\
-5.558 \\
2.369 \\
-6.050\end{array}$ & $\begin{array}{r}0.756 \\
-0.285 \\
0.142 \\
-0.452\end{array}$ & $\begin{array}{r}15.915 \\
-5.067 \\
4.007 \\
-9.491\end{array}$ \\
\hline Aged & 20-24 Years & $\begin{array}{r}1.117 \\
-0.616 \\
0.444 \\
-1.537\end{array}$ & $\begin{array}{r}8.107 \\
-7.684 \\
7.078 \\
-16.591\end{array}$ & $\begin{array}{r}0.681 \\
-1.302 \\
0.211 \\
-0.439\end{array}$ & $\begin{array}{r}5.795 \\
-14.581 \\
4.968 \\
-7.143\end{array}$ & $\begin{array}{r}0.989 \\
-1.080 \\
0.274 \\
-0.835\end{array}$ & $\begin{array}{r}8.969 \\
-14.145 \\
6.171 \\
-13.091\end{array}$ \\
\hline Aged & 25-29 Years & $\begin{array}{r}1.733 \\
-0.713 \\
0.418 \\
-1.302\end{array}$ & $\begin{array}{r}11.632 \\
-10.257 \\
7.979 \\
-17.099\end{array}$ & $\begin{array}{r}-0.148 \\
-1.181 \\
-0.011 \\
0.791\end{array}$ & $\begin{array}{r}-1.871 \\
-17.699 \\
-0.321 \\
13.289\end{array}$ & $\begin{array}{r}0.875 \\
-1.241 \\
0.082 \\
0.272\end{array}$ & $\begin{array}{r}11.906 \\
-25.007 \\
3.056 \\
6.336\end{array}$ \\
\hline Aged & 30-34 Years & $\begin{array}{r}1.774 \\
-0.774 \\
0.548 \\
-1.062\end{array}$ & $\begin{array}{r}12.923 \\
-12.557 \\
11.310 \\
-15.014\end{array}$ & $\begin{array}{r}0.168 \\
-1.170 \\
0.113 \\
0.554\end{array}$ & $\begin{array}{r}2.306 \\
-19.620 \\
3.522 \\
10.051\end{array}$ & $\begin{array}{r}0.782 \\
-1.189 \\
0.211 \\
0.142\end{array}$ & $\begin{array}{r}11.170 \\
-26.372 \\
8.089 \\
3.330\end{array}$ \\
\hline Aged & 35-39 Years & $\begin{array}{r}1.689 \\
-0.714 \\
0.382 \\
-1.025\end{array}$ & $\begin{array}{r}11.017 \\
-11.143 \\
6.743 \\
-12.457\end{array}$ & $\begin{array}{r}0.654 \\
-1.373 \\
0.120 \\
0.104\end{array}$ & $\begin{array}{r}7.450 \\
-24.148 \\
4.110 \\
2.367\end{array}$ & $\begin{array}{r}1.342 \\
-1.279 \\
0.179 \\
-0.202\end{array}$ & $\begin{array}{r}16.876 \\
-29.209 \\
6.872 \\
-5.200\end{array}$ \\
\hline Aged & 40-44 Years & $\begin{array}{r}1.773 \\
-0.716 \\
0.348 \\
-1.275\end{array}$ & $\begin{array}{r}12.438 \\
-12.747 \\
6.587 \\
-16.515\end{array}$ & $\begin{array}{r}0.724 \\
-1.184 \\
0.070 \\
0.121\end{array}$ & $\begin{array}{r}7.271 \\
-21.601 \\
2.214 \\
2.639\end{array}$ & $\begin{array}{r}1.412 \\
-1.154 \\
0.131 \\
-0.278\end{array}$ & $\begin{array}{r}15.466 \\
-25.790 \\
4.482 \\
-6.516\end{array}$ \\
\hline Aged & 45-49 Years & $\begin{array}{r}2.301 \\
-1.030 \\
0.278 \\
-0.933\end{array}$ & $\begin{array}{r}12.962 \\
-13.930 \\
4.840 \\
-11.107\end{array}$ & $\begin{array}{r}1.187 \\
-1.539 \\
-0.133 \\
0.804\end{array}$ & $\begin{array}{r}7.849 \\
-17.732 \\
-3.220 \\
11.749\end{array}$ & $\begin{array}{r}2.088 \\
-1.588 \\
-0.066 \\
0.358\end{array}$ & $\begin{array}{r}22.076 \\
-33.645 \\
-2.401 \\
8.674\end{array}$ \\
\hline Aged & 50-54 Years & $\begin{array}{r}1.445 \\
-0.860 \\
0.292 \\
-0.593\end{array}$ & $\begin{array}{r}10.521 \\
-13.780 \\
6.055 \\
-8.321\end{array}$ & $\begin{array}{r}0.159 \\
-1.367 \\
0.017 \\
1.405\end{array}$ & $\begin{array}{r}1.592 \\
-19.496 \\
0.392 \\
15.283\end{array}$ & $\begin{array}{r}0.961 \\
-1.326 \\
0.075 \\
0.788\end{array}$ & $\begin{array}{r}12.875 \\
-30.615 \\
2.683 \\
16.160\end{array}$ \\
\hline Aged & 55-59 Years & $\begin{array}{r}0.450 \\
-0.904 \\
0.217 \\
0.284\end{array}$ & $\begin{array}{r}5.272 \\
-18.286 \\
5.363 \\
4.149\end{array}$ & $\begin{array}{r}-1.153 \\
-1.350 \\
0.044 \\
2.308\end{array}$ & $\begin{array}{r}14.788 \\
-17.823 \\
1.034 \\
20.051\end{array}$ & $\begin{array}{r}0.338 \\
-1.140 \\
0.173 \\
1.233\end{array}$ & $\begin{array}{r}6.572 \\
-32.396 \\
6.127 \\
25.161\end{array}$ \\
\hline Aged & 60-64 Years & $\begin{array}{r}-1.924 \\
-1.039 \\
-0.133 \\
2.784\end{array}$ & $\begin{array}{r}18.655 \\
-10.264 \\
-1.903 \\
12.616\end{array}$ & $\begin{array}{r}3.159 \\
-1.005 \\
-0.113 \\
3.034\end{array}$ & $\begin{array}{r}20.399 \\
-8.189 \\
-1.541 \\
12.154\end{array}$ & $\begin{array}{r}2.457 \\
-1.378 \\
-0.175 \\
3.500\end{array}$ & $\begin{array}{r}36.027 \\
-16.953 \\
3.636 \\
24.514\end{array}$ \\
\hline Aged & 65 Years and Over $\_1$ & & & _1 & & $\begin{array}{r}3.773 \\
-1.306 \\
0.340 \\
0.961\end{array}$ & $\begin{array}{r}26.905 \\
-3.941 \\
2.751 \\
3.154\end{array}$ \\
\hline
\end{tabular}


(Continued below)

Tota1 A11 Ages

$$
\begin{array}{rrrrrr}
0.461 & 12.424 & -0.505 & -19.550 & -0.028 & -1.026 \\
-1.007 & -40.115 & -1.215 & -50.323 & -1.141 & -52.336 \\
0.152 & 9.892 & 0.057 & 5.374 & 0.095 & 8.415 \\
-0.347 & 15.053 & 0.463 & 25.590 & 0.110 & 6.104
\end{array}
$$

Data 1986Q1 to 2014Q2

Each sub-population has a matrix with coefficients in the first column and the t-statistics in the second. R Squared values are in Table 2. A _ 1 indicates insufficient valid data. The underline is used to denote negative numbers.

Table 2 R squared and Number of Valid Data Points by Age and Gender Groups

Male Female Total

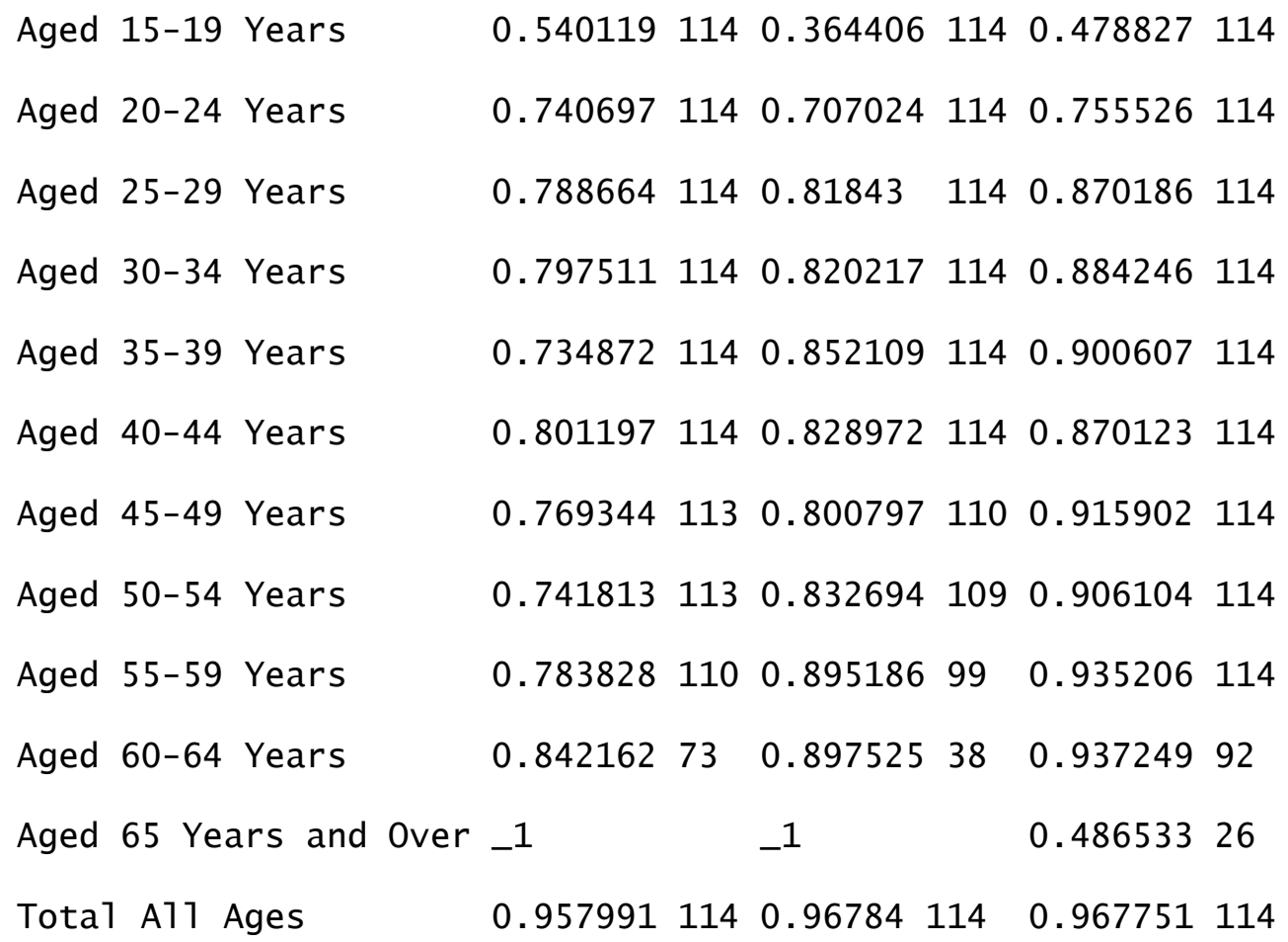


Table 3 Mean Probability of Search by Persons without Jobs at Observed Mean Participation Rates

$\begin{array}{lcccr}\text { Age Group } & \begin{array}{c}\text { Participation } \\ \text { Male }\end{array} & \begin{array}{c}\text { Probabi1ity } \\ \text { Of Search }\end{array} & \begin{array}{c}\text { Participation } \\ \text { Female }\end{array} & \begin{array}{r}\text { Probabi1ity } \\ \text { Of Search }\end{array} \\ \text { Aged 15-19 Years } & 44.6 & 0.179 & 44.0 & 0.163 \\ \text { Aged 20-24 Years } & 73.7 & 0.342 & 62.8 & 0.184 \\ \text { Aged 25-29 Years } & 85.2 & 0.410 & 63.7 & 0.129 \\ \text { Aged 30-34 Years } & 87.7 & 0.389 & 63.1 & 0.109 \\ \text { Aged 35-39 Years } & 88.9 & 0.375 & 68.9 & 0.118 \\ \text { Aged 40-44 Years } & 89.2 & 0.345 & 75.3 & 0.137 \\ \text { Aged 45-49 Years } & 89.1 & 0.329 & 77.2 & 0.126 \\ \text { Aged 50-54 Years } & 86.9 & 0.282 & 72.1 & 0.096 \\ \text { Aged 55-59 Years } & 80.2 & 0.176 & 59.1 & 0.048 \\ \text { Aged 60-64 Years } & 56.3 & 0.040 & 36.5 & 0.012 \\ \text { Aged 65 Years and 0ver } & 14.7 & 0.002 & 6.6 & 0.001\end{array}$

